\title{
Watching young children 'play' with information technology: Everyday life information seeking in the home
}

Lisa M. Given ${ }^{\mathrm{a}}$, Denise Cantrell Winkler ${ }^{\mathrm{a}}$, Rebekah Willson ${ }^{\mathrm{b}}$, Christina Davidson ${ }^{\mathrm{c}}$, Susan Danby ${ }^{\mathrm{d}}$, Karen Thorpe ${ }^{\mathrm{e}}$

\section{Highlights}

- Young children engage with technology in artistic play, socio-dramatic play and literacy/numeracy.

- Everyday life information seeking (ELIS) way of life and mastery of life are modeled in children's activities.

- Video data provide a glimpse into technology use by young children in their homes.

\begin{abstract}
Research on how young children use information to orient themselves in daily life and to solve problems (known as everyday life information seeking or ELIS) has not been conducted, indepth, in information science. This exploratory observation study examines how 15 Australian preschool children (aged three to five) used information technologies in their homes to orient themselves in daily life and to solve problems. Children engaged in various ways with the digital technologies available to them and with parents and siblings during play activities. The results explore the value of artistic play, sociodramatic play, and early literacy and numeracy activities in shaping young children's 'way of life' and 'mastery of life' as outlined in Savolainen's (1995) ELIS model. Observed technology engagement provided an opportunity to explore children's social worlds and the ways that they gathered information during technology play that will inform future learning activities and support child development. By using ELIS theory as an analytic lens, the results demonstrate how children's developmental play with technology tools helps them to internalize social and cultural norms. The data also point to the type of capital available to children and how that capital contributes to children's emerging information practices.
\end{abstract}

\footnotetext{
${ }^{a}$ School of Information Studies, Charles Sturt University, Locked Bag 588, Wagga Wagga, New South Wales 2678, Australia

${ }^{\mathrm{b}}$ Department of Computer and Information Sciences, University of Strathclyde, Livingstone Tower, 26 Richmond Street, Glasgow, Lanarkshire G1 1XH, United Kingdom

${ }^{c}$ School of Education, Charles Sturt University, Locked Bag 588, Wagga Wagga, New South Wales 2678, Australia

d School of Early Childhood, Queensland University of Technology, GPO Box 2434, Brisbane, Queensland 4001, Australia

${ }^{\mathrm{e}}$ School of Psychology and Counseling, Queensland University of Technology, Victoria Park Road, Kelvin Grove, Brisbane, Queensland 4059, Australia
} 


\section{Introduction}

Many studies in information science examine children and young people's information behaviors, including technology use (Bilal, 2005; Cooper, 2002; Danby, Mallan, \& Butler, 2010; Dresang, 2005; Foss et al., 2012; Spink, Large, Nesset, \& Beheshti, 2008). Similarly, many large-scale studies document the reach of technology in young people's lives, particularly for older children. The Pew Research Center in the United States found 93\% of 12-17 year olds accessed the internet (Lenhart, Purcell, Smith, \& Zickhr, 2010) and 82\% owned at least one mobile device (Madden, Lenhart, Duggan, Cortesi, \& Gasser, 2013). The Australian Kids Online project found that $96 \%$ of children aged 9-16 used the internet at home, with three in five having access to mobile devices (Green, Brady, Ólafsson, Hartley, \& Lumby, 2011). However, very few large-scale studies focus on technology use in preschoolers' lives. Zevenbergen and Logan (2008) found that most Australian children aged four and five had access to computers in their homes or other locations. Vandewater et al. (2007) found that in homes of children aged 6 months to 6 years around 80\% have computers (p. 1009). More recently, education researchers in Australia have examined young children's experiences with technology (Danby et al., 2013; Danby, Davidson, Edberg, Breathnach, \& Thorpe, 2016; Davidson, 2010; Davidson, 2012a; Davidson, 2012b; Davidson, Danby, Given, \& Thorpe, 2014), demonstrating that this is a significant and growing area of study. One large-scale study in the United States found that 38\% of children under age 2 have used a mobile device, compared to only $10 \%$ two years earlier (Common Sense Media, 2013, p. 9). Thus, despite the increasing ubiquity of digital technology in children's lives, current studies in information science provide few details as to how young children engage with technological tools.

This paper presents the results of a study that used video recordings to observe children's use of technology. By using Savolainen's (1995) everyday life information seeking (ELIS) theory as a frame for analysis, which examines how individuals gather and use information to orient them and solve problems in daily life, the data provide a glimpse into the technology-related activities shaping the everyday lives of young children. The paper presents a unique analytic approach to studying children's daily activities, and also extends the ELIS framework beyond an exploration of the "health issues, consumer problems, housing, and various kinds of hobbies" (Savolainen, 2004, p. 7) that have been the focus of myriad studies of adults and older children's everyday information needs for decades.

\subsection{Problem statement}

Within information science research, young children have received relatively little attention. Young children, aged three to five, are a challenging group to study, often due to their emerging literacy skills and the fact that their pre-school status may make this age group more difficult to access for research purposes. The everyday life information seeking of adolescents and pre-teens is an area of increasing study (Agosto \& Hughes-Hassell, 2006; Lu, 2010; Meyers, Fisher, \& Marcoux, 2009); however, this has not been the case with young children, until recently. While there is a dearth of research in this area, there is research that demonstrates this group is increasingly using digital technologies (Common Sense Media, 2013; Vandewater et al., 2007; 
Zevenbergen \& Logan, 2008), including those designed for adults. At the same time, companies continue to develop technology specifically designed to target emergent literacy in young children and encourage parents to buy devices to help their children develop literacy skills (Marsh, Hannon, Lewis, \& Ritchie, 2015). This exploratory research addresses the questions: How do young children use technology in their homes? and In what everyday life information seeking activities do young children engage when using digital technologies?

\section{Literature review}

This review of the literature covers everyday life information seeking (ELIS), children's information seeking, and children's use of technology. Although these studies do not take a child development perspective per se, child development - the physical, cognitive, emotional, and social growth and development an individual experiences (Levin, 2011) - is a part of how children interact with the world, including how they seek and use information and technology. The literature review begins with an exploration of research in the field of education to set the context for the more focused discussion of ELIS and specifically, children's information activities.

\subsection{Studies of young children and technology in education}

For decades, education researchers have explored preschoolers' experiences with technology, focusing on pedagogy and/or curriculum in school environments (Burnett \& Merchant, 2014; Clements \& Sarama, 2007; Gimbert \& Cristol, 2004; Kalogiannakis \& Zaranis, 2012; Willett, Robinson, \& Marsh, 2009; Theobald et al., 2016). Using computers to teach literacy skills to young children is one key area of this research (Burnett, 2010; Labbo \& Reinking, 2003; Lankshear \& Knobel, 2003; Plowman, Stephen, \& McPake, 2010a, 2010b; Stephen, McPake, Plowman, \& Berch-Heyman, 2008). Most studies of early literacy and technology focus on skills instruction in formal childcare environments, with technology employed as the "deliverer of literacy" rather than a tool used to make connections between different areas of children's lives (Burnett, 2010, p. 258). Education researchers also note a rise in marketing (and purchasing) of educational media devices and programs designed for home use (Dhingra, Sharma, \& Kour, 2009; Buckingham \& Scanlon, 2001). Gutnick et al. (2011) posit that the media habits of young children, which often involve watching online videos, may be due to the hours young children spend at home and the lack of age-appropriate content available on over-the-air television in some countries. Researchers have debated the merits and value of media viewing by young children, particularly from a developmental standpoint (Desmond \& Bagli, 2008; Ellis \& Blashki, 2004; Marsh \& Bishop, 2012; Schlembach, 2012).

\subsection{Young children, information seeking and the use of technology in everyday life}

Recent studies on children and teen's access to and use of technology have focused predominantly on older children. For example, 18\% of 8-11 year-olds in the United Kingdom have their own tablet computers, and tablet use among 5-15 year-olds has dramatically increased from 14\% to $41 \%$ between 2012 and 2013 (Ofcom, 2013). While many studies do not have data on young children, the Ofcom study found that $28 \%$ of $3-4$ year-olds use a tablet at home, with $12 \%$ using a tablet to go online. Holloway and colleagues (2013) found that, worldwide, children 
are going online at younger ages; $25 \%$ of 3 -year-olds and $50 \%$ of 5 -year-olds in the United States go online daily, while 70\% of 3-4 year olds go online "sometimes" in Sweden. Recent studies by education researchers in Australia also explore young children's practices using technology, including their online searching (Danby et al., 2013; Danby et al., 2016; Davidson, 2010; Davidson, 2012a; Davidson, 2012b; Davidson, et al., 2014; Ekberg, Danby, Davidson, \& Thorpe, 2016). In information science, however, few studies explore very young children's technology practices. Although some research includes the experiences of four and five-yearolds in the home (McKechnie, 2004), the primary focus is on older children (Foss et al., 2012) and is typically related to school-based activities (Bilal, 2002; Large, Beheshti, \& Rahman, 2002). Spink and Heinström (2011) note that three-year-olds are not believed to engage in information behavior beyond the immediate moment in time they are experiencing. Although four and five year old children are shown to search the web, type words, browse results, complete web queries, and make relevancy judgments (Spink et al., 2010), this area of research is quite nascent in the field. Technology companies may recognize the growing importance of this age group, and work with young children to create new tools (Barack, 2013); however, more research in information science is needed to explore the roles of digital technologies in young children's daily experiences.

Although studies of adults' ELIS (i.e., information seeking for non-occupational tasks, such as health or hobbies) are prevalent (e.g., Connaway, Dickey, \& Radford, 2011; Given, 2002; McKenzie, 2003; Park \& Lee, 2013; Westbrook, 2009), very few studies explore children's ELIS activities. Todd (2003) noted that teens did not use libraries or other information agencies for ELIS and often did not know where to seek help for ELIS needs. Agosto and Hughes-Hassell (2006) examined inner-city teens' information needs through the lens of ELIS, with a focus on the transition to adulthood. The study showed the need for linking information seeking research to adolescent developmental theory (Agosto \& Hughes-Hassell, 2006). Meyers et al. (2009) studied children aged 9-12 and found their information needs were concrete and focused on short-term activities, such as school, relationships, sports and hobbies. Lu (2010) surveyed 11 and 12 year old children and found that they engaged in five types of information seeking behavior to cope with daily life: to solve problems, for escape, for transition, to change mood, and, for information avoidance. As information science researchers are only beginning to explore children's ELIS activities, it is not surprising that the experiences of very young children have not yet been examined in this context. This research addresses this gap by exploring technology use data drawn from the home environments of preschool-aged children.

\subsection{Everyday life information seeking (ELIS): A brief overview}

Before discussing the results of the study, it is important to outline specific elements of the theory of everyday life information seeking as it has emerged in information science, which informed the analysis. ELIS involves the "acquisition of various informational (both cognitive and expressive) elements which people employ to orient them in daily life or to solve problems not directly connected with the performances of occupational tasks" (Savolainen, 1995, pp. 266267). Meyers, Fisher, and Marcoux (2009) describe the ELIS of children as concerning "how children seek and use information for meeting their developmental needs, investigating career and lifestyle choices, and building relationships with friends and family members" (p. 304). ELIS shapes understandings of how people engage in information activities outside of school 
and work environments; it is grounded in Bourdieu's theory of habitus or, as Savolainen (1995) describes it:

...a socially and culturally determined system of thinking, perception and evaluation, internalized by the individual. [As] habitus manifests the incorporation of norms and social expectations within an individual ... [it] renders a general direction to choices made in everyday life by indicating which choices are natural or desirable in relation to one's social class or cultural group (pp. 261262).

Savolainen (1995) introduced the concepts of way of life and mastery of life to explore the practical manifestations of habitus (p. 262). In brief, way of life (or the order of things) refers to the preferences people give to the various activities in which they engage (e.g., the amount of time devoted to one activity versus another). Mastery of life is the care that an individual takes in shaping those preferences, so that the choice he/she makes fit with his/her own values and is coherent with one's personal life path. Societal and cultural values provide models for mastery of life; thus, the culture "not only directs habits and attitudes to working life but also to spending leisure time, for example, the role of book reading and watching television" (p. 264). In addition to socialization to these culture models, individuals also establish "daily practices of everyday life [that] begin to establish themselves in a natural order, being perceived as self-evident. The concrete examples received at home and at school influence this developmental process" ( $p$. 264). All these experiences shape individuals' information orientations, which then affect information seeking and use behaviors.

For young children, play can be considered their way of life or those everyday activities (Savolainen, 1995, p. 262) in which they engage. Mastery of life is a useful approach to explore how young children "orient themselves in (typical) problem situations and seek information to facilitate problem solving" (Savolainen, 1995, p. 265) and learn the skills needed throughout life. The ELIS activities of children can also vary widely. In speaking to children aged 9-13, for example, Meyers, Fisher, and Marcoux (2009) found many examples of children's ELIS; these included looking on the Internet for reviews of video games and talking to friends and a coach about how to properly execute a soccer move. Pre-teens, of course, have different interests, autonomy, mobility, and developmental capabilities from young children, who are understudied in the context of their ELIS activities.

\section{Research design}

This study explored young children's (i.e., aged three to five) experiences using information technology in the home. The research was part of a larger study that included data collection in preschools (Australian Research Council, DP110104227). The full project explored the extent to which web use was a part of home and preschool-based experiences, examining both the tools used and the social and technological interactions that occurred during the children's use of technology. Participants were recruited from eight early childhood centers in Queensland, Australia. Research ethics boards at the two universities involved in the study granted ethics approval for data collection in both home and preschool environments. The full study design included observational research in nine classrooms, surveys of teachers and parents, and observational research in a sample of 15 children's homes. 
This report analyzes results from the home-based dataset, which comprised video recordings made by parents of their children's interactions with information technologies and with other people in the home environment. Parents set up the researcher's video camera in a location where their children were interacting with technology at an angle to capture both the screen and the child. Over a one-week period, parents recorded their children's use of technologies during typical, everyday activities (see Given et al., 2016, for details on the observational method). The full dataset comprised 29 hours of video recording, showing children using laptops, desktops and a range of handheld devices. Individual sessions (i.e., a child engaging with technology in a single sitting) ranged from less than two minutes to more than 80 minutes. The average session lasted 16 minutes. The total number of sessions ranged from a low of two sessions for one child recorded on a single day, only, during the week of data collection, to a high of 29 sessions for another child, with sessions recorded on every day of the data collection period.

The video recordings were analyzed using an inductive, thematic approach to explore emergent themes related to preschoolers' everyday activities. A detailed descriptive analysis was also completed using a modified seating sweeps approach (Given \& Leckie, 2003); this involved the video data being coded as though the researchers were in the physical space and observing the children's behaviors, directly. The seating sweeps method provides a systematic way to record details of observed behavior related to who is in a space, including the activities in which they engage, the locations of the activities, and the personal belongings they bring with them (Given \& Leckie, 2003). Using the young child participant as the focus of the analysis, data were coded pertaining to the child's technological engagement. Location (e.g., dining room), materials (e.g., tablet), and activities (e.g., singing) were the three main points of observation. Other people present in the space (e.g., parents and siblings) were noted, as well as any interaction that occurred. Children's interactions with materials other than technologies (e.g., dolls) also were coded for analysis. At times, children engaged in multiple activities or had multiple materials and/or companions with them while engaging with technology. One researcher coded the data, which were then checked by two other researchers for face validity. Although some of these data are mentioned here, to provide context for the thematic analysis, the full descriptive results of the observational analysis are published elsewhere (Given et al., 2014).

ELIS theory was used as an analytic lens to explore young children's engagement with technology; thus, emergent themes were documented pertaining to way of life and mastery of life. The participants engaged in various free play activities, from watching YouTube videos to playing computer games. In $45 \%$ of the recorded instances children engaged with the devices on their own and in silence; they clicked on apps, moved between YouTube videos and were actively absorbed in the activities. These independent activities, without self-talk, indicate a way of life that many adults employ (i.e., preferences people give to the various activities in which they engage, such as the amount of time devoted to one activity versus another). In $55 \%$ of instances children interacted with siblings and parents or engaged in self-talk while using technology. Verbally communicating with people and self are indicators of social and emotional development. All these activities and interactions demonstrate the complexity of young children's experiences and preparation for their future adolescent and adult lives. When viewed through the lens of ELIS theory, the activities point to early steps in the 'mastery of life' that define an individual's everyday information behaviors. 


\section{Results and discussion}

One key consideration in any analysis of ELIS activities is defining what constitutes everyday life for the participants under investigation. For adults, information practices regarding personal health, leisure, entertainment, real estate, and other topics are typically regarded as ELIS-relevant (Case \& Given, 2016). So, what constitutes everyday life for very young children? And what types of information might these children need, given that most are emerging (rather than proficient) readers? Research in child development provides guidance in this regard. The vast area of research in child development includes theories and practices for children from conception to age 8 involving their physical, cognitive, social, linguistic, moral, spiritual, and emotional changes unique to childhood. What adults may refer to as play, for example, does not simply comprise leisure or entertainment activities. Rather, very young children "play" at being adults; preschoolers use this time to learn how to make choices, to engage with the world, to interact with peers and family, and to gather information to support their personal development (Danby, Davidson, Theobald, Houen, \& Thorpe, in press). Bodrova and Leong (1998), in discussing Vygotsky's social constructionist approach to children's cognitive development, note that play is essential to more than the development of discrete skills, but to children's whole development. Children's drawings, singing, and other forms of artistic expression, enable them to express their ideas, feelings and opinions about their worlds. These "opportunities to create through writing, music, art, drama, and dance can greatly enhance student motivation and provide an outlet for the creativity evident in all young children" (Charlesworth, 2011, p. 469). Children also model particular activities, such as self-care or early literacy and numeracy, all of which are vital for social development. These activities are an important aspect of development, as, "There's no doubt that we learn in response to experience, but it's also true that through play, we create many of the experiences from which we learn" (Elkind, 2009, p. 8).

Young children can interact playfully with a range of digital technologies (Danby et al., in press; Marsh, Hannon, Lewis, \& Ritchie, 2015; Plowman et al., 2010a, 2010b; Scriven, Davidson, Danby, Thorpe, \& Given, 2013; Yelland, 2010a). Young children also use technology with purpose, allowing them to make sense of their activities and accomplish tasks as they interact with and between technologies (Davidson, 2012b). Using digital technologies, however, requires children to learn and use multi-literacies (a repertoire of flexible skills across a range of media) and in multiple modalities, including written, visual, aural, gestural, linguistic and tactile experience (Thorpe et al., 2015; Verenikina \& Kervin, 2011; Yelland, 2010a, 2010b). The place of computers in the everyday play activities of young children and, by extension, their social development through technology-enabled activities, is a key focus of the sections that follow.

\subsection{ELIS practices of young children}

In the video dataset, children were observed using desktop and mobile devices to listen to music, look at family photos, watch online videos, and play computer games. To the outside observer, these activities may appear only to mirror the computer-based activities in which adults engage in their leisure time. However, an in-depth analysis of these activities reveals the complex ways that young children engage with technology and with their everyday worlds. The preferences that children demonstrate in their technology use reflect their way of life (Savolainen, 1995) as they 
make sense of their worlds. Some children were observed playing with the same iPad app or watching the same YouTube video for extended periods of time; they often sang along or anticipated the content coming next from the computer screen, demonstrating a deep familiarity with these preferred programs. Just as adults may choose familiar reading genres (Ooi \& Liew, 2011; Ross, 1999) or may return to familiar sources of information when faced with everyday problems (Connaway, Dickey, \& Radford 2011; Fisher, Naumer, \& Durrance 2005; Savolainen, 2007), these young children engaged with activities that were familiar and interesting to them. These behaviors are consistent with early findings in child development research showing that repetitive and ritualistic behaviors are present in young children, particularly ages two to four, after which time these behaviors decrease. For example, these ritualistic behaviors are believed to have a psychologically adaptive function, such as developing adaptive, purposeful activities or serving social and emotional needs of self-control and emotional regulation (Evans et al., 1997). Similarly, Marsh's $(2005,2006)$ work explores ritual, performance, and identity in young children's popular culture, with implications for literacy curriculum development. However, the children in this study also engaged in activities that demonstrate the beginnings of mastery of life (Savolainen, 1995). As noted earlier, children's play activities allow them to gather information to support personal development, ranging from self-expression to early literacy skills, which are necessary for social development. Here,

children appropriate available cultural resources in their play, games and cultural activities, [which] is a stronger notion than active participation. It implies to take over and make one's own.... In this view children collectively become a part of adult culture - that is, contribute to its reproduction - through their negotiation with adults and their creation, with other children, of a series of peer cultures (Evaldsson \& Corsaro, 1998, p. 379-380).

The young children observed in this study had many technological devices with which to engage, including iPads, laptop computers, desktop computers, smartphones, iPod touches, game consoles, and interactive e-reading devices. Some of the devices were designed specifically for children to develop reading skills (e.g., the Storio ${ }^{\mathrm{TM}}$ educational tablet). Parents and siblings were also observed aiding the young children in their play by helping them to set up and use the technology, and by engaging with the content the digital technologies provided by helping to locate letters on the keyboard. These young children were encouraged to interact with digital technologies, which provided them with cognitive resources, based on their own experiences. The access to technological devices in the home, the involvement of other people in the use of technology, and the experiences they were given with digital technology shaped these children's play experiences. Savolainen (1995) discusses the importance of material, social, and cultural (cognitive) capital as the "basic equipment" in finding and using information, the distribution of which, "in relation to capital owned by others determines the total value of the material, social, and cultural capital, thus determining the basic conditions of way of life and mastery of life" (Savolainen, 1995, p. 267).

The digital devices the children used (along with the accompanying electricity or battery needs and internet connectivity) are examples of the material capital available to the children, determining in which types of activities they can engage and what kinds of literacies they can learn. The parental and sibling interactions are examples of the social and cultural capital 
available to the children, shaping play experiences through the supports given to the children and the types of content they are directed toward. Young children engaged with technologies in various ways, repetitively demonstrating the cultural (cognitive) capital available to them based on their education and life experience (Savolainen, 1995). The results presented here are grouped by the types of activities observed and analyzed alongside the key principles of ELIS theory.

\subsection{Artistic play}

Many of the children in this study engaged in artistic pursuits with technology, such as drawing and singing. Interestingly, there was a lack of feedback mechanisms in many of the applications and programs accessed by these young children. Many watched YouTube videos, repeatedly, receiving information from the screen, but without any direct encouragement or positive reinforcement from the system (e.g., sounds, visuals, etc.). Tina, for example, sang along with a Barbie video, while holding a Barbie doll and mirroring the action on the video; later, she used a dolphin cookie-cutter to follow along with the actions of an animated dolphin, on screen (i.e., an excerpt that has also been analyzed, in depth, using a conversation analysis approach in Scriven et al., 2013). As Tina was alone at the computer, and as the online video was not designed for system-directed child interaction, Tina's engagement with the content was driven by her own desires and interests. Rosielyn, on the other hand, asked her mother - and was then promptedto sing the hokey-pokey song playing on her device. Eliason and Jenkins (2012) note the importance of positive verbal feedback with young children, encouraging "affirmation and praise of the children's work" (p. 357). They note that the "efforts and process are more important than the product" with young children, whose art may be very "personal, experimental, and not intended to look like something" (p. 355).

Lieberman, Fisk, and Biely (2009) also note the importance of reinforcing behaviors in children's games, providing a number of recommendations for system design. In this study, Lara used a drawing app on her iPad, covering the screen with pictures of hearts and other shapes until the main picture was no longer visible. As she worked on the image, the program responded with encouragement, saying "That looks great!... You are a natural artist." These kinds of programs can foster confidence and self-esteem by providing positive reinforcement of children's activities (Miller \& Robertson, 2010). As Trawick-Smith (1997) notes,

an interesting feature of children's drawing is repetitive practice. Once children begin making small, circular scribbles, they draw these over and over again on paper. Once they begin to draw heads, they fill pages with them.... This repetitive practice may be an effort to gain mastery over newly acquired abilities (p.227).

When combined with children's personal preferences for particular activities, such positive reinforcement can also help to shape mastery of life by guiding children's value systems and modeling the norms and social expectations that inform the practical manifestations of habitus. A child's information needs and seeking behaviors, then, will grow from these early beginnings. As a child engages in an artistic activity, and is encouraged to do so, they may choose to pursue further activities and search for resources that will support those interests. This was evident in Tina's case, for example, as she repeatedly sang and searched online for more songs related to her chosen interests (see Scriven et al., 2013). 


\subsection{Sociodramatic play}

In their guide to early childhood curriculum development, Eliason and Jenkins (2012) recommend providing various props for the creation of dramatic play areas in classrooms to model, for example, restaurants, offices, or bakeries. They note, "Dramatic Play is especially enjoyed by 3 - to 8-year olds because they like pretending. It is easy for a child to become a police officer, farmer, mother, father, beautician, or whatever role [physical props provided to children] may inspire" (p. 365). Bredekamp and Copple (1997) also note the importance of providing children "small objects to sort and count; pegboards and beads to string; clothing and things that zip, button and tie for dress-up play; dolls and accessories; drawing and writing materials; scissors, paint and clay" to help them in the development and practice of fine motor skills, along with opportunities to practice functional, daily life skills, such as pouring milk, setting the table, eating and dressing (p. 104). As Hughes (2010) notes, one of the key socialization benefits of dramatic play is that "it allows children to experiment with a variety of roles; to try on those roles, as it were, and determine their appropriateness; and to develop a better understanding of the roles of other people" (p. 253). This type of socialization is closely linked to mastery of life that comes from ELIS activities, where individuals must integrate social norms and expectations with their own personal desires for their life direction. Part of mastery of life is the idea of project of life, or the larger life plan that has attached values and goals (Savolainen, 1995). For children, exploration of the environment and learning about their world is a project of life.

In a digital environment, the computer serves as a surrogate prop and social object, providing inspiration from the inclusion of specific sounds, images and other features to engage children's imaginations. Jaiden, for example, was observed going into a pizza shop on his computer and selecting the game Pizzatron 3000. He plays the game, which requires him to put toppings on pizza bases. Jaiden also engaged in pretend play when he used computer speakers to imagine that the sound they made was a gun that his sibling could attach to a toy truck (see Danby et al., in press, for a further analysis of this example). Eadie clicked on an image of a bridle and put it on the horse on the screen; she then used both forefingers on the mouse pad to put a blanket on the horse. Lara engaged with a baking program and talked through the steps in the process, from listing the ingredients to describing her activities, such as "crack the egg" and "mix them together". Lara also played in an online makeup room, where she chose to paint the on-screen model's nails by clicking colors on the mouse pad. At one point, she held her own hand up to the screen, spreading her fingers to mirror the action of the hand shown in the activity, and then matching her own skin color to the choices on the screen. These types of games are important in the "developmental continuation of play [as they] are dependent on mutually accepted rules of procedure in a specific frame" (Evaldsson \& Corsaro, 1998, p. 378).

Computer games and applications designed for children also allow children to engage in dramatic play in ways that are similar to how children play with physical props. However, there are also a number of limitations to the affordances that technologies can provide. In considering Lara's experience with food preparation, for example, the words of Eliason and Jenkins (2012) must be considered: "The sensory experiences in food activities offer the greatest learning value. In addition, children enjoy working with and manipulating food—mixing, measuring, pouring, 
stirring, and eating" (p. 134). While one could argue that physical props are also limited in this regard (e.g., a child cannot experience the smell of a plastic cake in a plastic oven), the tactile experiences of manipulating bowls, spoons, and oven knobs cannot be replicated in a digital environment. Similarly, the potential for information seeking to support a young child's tactile learning experiences are also limited by the digital experience. Although the sights and sounds of the kitchen may be modeled online, the tactile experience of kneading bread dough, or the smell and taste of fresh bread, requires other forms of engagement for young children. As Branscombe, Burcham, Castle, and Surbeck (2014) note,

Children are constantly engaged in learning. As they experience their daily routines they make decisions, when, where, and how they learn. As they engage with tasks ... they experience being the one who makes or decides something. For example, as they pour milk on their cereal, they construct hypotheses about solids and liquids as well as about quantity (p. 30).

Cooking is just one of many life tasks where learning and information acquisition are linked to embodied practices (e.g., Lloyd, 2011; Olsson, 2010; Somerville \& Lloyd, 2006 ; Veinot, 2007). And yet, the role of the body in shaping information practices (regardless of a person's age) has only been explored in a few studies in the field. The body is a source of sensory information, becoming "a communicator of practice and a symbol of community and professionalism that reflects the discourse in which the body is situated socially, politically and historically" (Lloyd, 2007, p. 188). For young children and adults, alike, mastery of life will only be achieved when people can access the full range of life's experiences — gained both through knowledge and sensory experience - and then make choices that are relevant to their future life paths.

\subsection{Early literacy and numeracy}

In addition to artistic play and sociodramatic play, many children observed in this study engaged in literacy and numeracy activities. At times, children used a range of computer programs and online resources designed to promote early literacy and numeracy. In other cases, children typed words in a search box, searched for images (rather than texts), or talked about word meanings while engaging in other activities. These activities are examples of cultural capital in children's lives (Savolainen, 1995). In this excerpt (which has also been examined, in depth, using a conversation analysis approach in Davidson, Danby, Given, \& Thorpe, in press), Henry spells out a word while looking for information online on the topic "How do they make paper white?" He engages with his father as he uses Google to find the information:

Henry: How do they make paper white?

Dad: $\quad$ Ok type it in...one button at a time, leave spaces in between the words, okay? I'll leave you to it and be back to check it in a minute. [Dad leaves the room]

Henry: [Places his index fingers carefully on the keys and begins to find and select the letters. He types three letters, then backspaces, checking the search box after each letter]

Henry: How [After saying the word, he looks on the screen and types two more letters].

Dad: [Returns and looks at the screen]: How you going? That's it! 'How do...' Keep going! 
Henry: 'How do they...' I don't know how to do 'they' .

Dad: Yeah, sound it out...

Henry: T... but I don't know the other ones.

Dad: $\quad$ Say 'the'...

Henry: I don't know [He slouches back in the chair]

Dad: $\quad$ Start talking and I'll help you as we go.

Henry: [Starts typing random letters].

Dad: Henry, you know what letter it starts with so type in that letter, please. [Dad hits the backspace button sharply]. They.

Henry: [Sits up and types the letter T; the computer auto-fill puts an R after the T].

Dad: The computer's messy so you have to press $\mathrm{R}$ backspace $\mathrm{T}$ if you want... so the computer's saying if you want T...for 'they'... So what you've realized is that once you start to type letters [he points to the dropdown box] Google tries to guess...

Henry: Yeah.

Dad: It tries to guess what you are going to say. But just because things are popping up there, it doesn't mean you have to choose one of those things.

Henry: Yeah, I know.

When they were using programs designed specifically for literacy and numeracy activities, most children engaged quietly and independently with these programs. In a few cases, the children were observed engaging with parents during these activities. Ashton, for example, sounds out the words using the Reading Eggs program (a fee-based, education subscription education program that uses lessons with games and songs to teach children to read), as his mother completes the activities on the screen:

Ashton: Mum, mum do you know how to spell water? Do you know how to spell water? Mum: Spell water? Yeah...does it have 'at' in it? Does it? [Ashton looks at the screen and names some of the pictures appearing (e.g., bat, cat) as Mum completes the activities. Mum sounds out the words as the pictures appear and Ashton mimics her pronunciation]

Similarly, Henderson looked for the letter Q to complete the word 'quilt' on the screen, with his mother's help and with the computer program's prompting:

[A picture of a bed and the word 'quilt' appear on screen]

Mum: Look at the word 'quilt'

Laptop: 'Help Mac find the missing letters...' [The Q is now missing]

Mum: What did it start with?

Henderson: C, K, J... [Henderson tries to match the letters to the $\mathrm{Q}$ sound]

Mum: Quilt [she says, in response to the appearance of an on-screen graphic of a quilt; Henderson looks at the keyboard to find the letter Q]

Mum: On the left

Henderson: [finds the key and presses $\mathrm{Q}$ to complete the word on screen]

In this study, parents co-viewed on-screen content with their children in $48 \%$ of the total cases. 
In $45 \%$ of these observed instances, however, child participants viewed videos and programs alone, with no opportunity for feedback from another person. This raises questions about the educational value of the children's engagement with the material, in the context of evidence related to the importance of parent scaffolding of young children's media use. Plowman, Stevenson, McPake, Stephen, and Adey (2011) note that preschoolers' opportunities for learning are created in homes by parents who provide resources, set up activities and monitor children's use and progress. Courage and Setliff (2009) outline a number of debates as the role of television and video viewing by infants and toddlers, noting that these children are sensitive to media and gain information from them long before age three. However, they also state that young children are "social beings, and much of their cognitive development emerges in a social context" (p. 75). In reviewing several studies of young children's viewing of videos and other media, Courage and Setliff (2009) note young children often watch videos alone; however, when co-viewed with parents who provide scaffolding (e.g., describing, labeling, pointing), children's responsiveness, attention span, learning, and comprehension can all be increased.

In information science, while we know the prevalence and value of serendipity or other forms of what is often labeled as passive information seeking on the part of adults and youth (e.g., Bjorneborn, 2008; Erdelez, 2005; Foster \& Ford, 2003), more research is needed on young children's experiences. What do preschoolers gain from viewing media online? How does engagement with the material foster information needs and seeking of children at this young age? What social and cultural models are shaping young children's mastery of life? These questions are particularly important now that content is available whenever and wherever children want, not only on TV sets (viewed at scheduled times) in their bedrooms but also on computers, mobile phones, and handheld media devices, like iPods and iPads (Gutnick et al., 2011, p. 23).

\section{Conclusion}

Overall, the results of this observational study present a number of rich findings related to young children's ELIS activities, as well as the types of material, social, and cultural capital available to these children. As these children engage in artistic and sociodramatic play, as well as early literacy and numeracy activities, they learn about the nature of their social worlds and gather information to shape future learning activities. These practices are similar to what an adult does when engaging in an activity for the first time or encountering a new situation. Although the technological resources children use may have some limitations (e.g., the lack of a complete sensory experience), they do offer a number of unique benefits (e.g., computer-based positive reinforcement of learned activities) that support child development. When used as a lens for analysis, ELIS theory provides one way to understand how children's developmental play activities in an online environment fit with their daily experiences. By modeling the adult world, and by being exposed to social and cultural norms while engaging in everyday play activities, young children can internalize these elements and set themselves on a life path that will meet their developmental needs. ELIS also provides a way to better understand the type of capital that children have in their environment, and how this capital contributes to their way of life. Their information practices, while still emerging at this age, are shaped by the sources, tools, and people with which they engage in their technology-enabled activities. 
Although this research project was not designed to explore the implications of children's play on the provision of library supports to young children and their parents, directly, the findings point to interesting areas of further development for research and practice in this area. Public libraries, for example, could investigate the provision of particular resources to support children's digital play given the findings presented here. Children's librarians, for example, could integrate the concept of technological play as a part of children's ELIS, thereby extending library programming to further support the information needs of children and their families from a developmental perspective. Additional research in this area is warranted.

Another area for further research relates to a limitation with using observational data for analysis - i.e., that observational data, alone, cannot allow for a full exploration of the ELIS typology. Savolainen (1995) outlines four dimensions of mastery of life: 1) optimistic-cognitive (i.e., a strong reliance on positive outcomes for problem solving); 2) pessimistic-cognitive (i.e., acceptance that a problem may not be resolved optimally); 3) defensive-affective (i.e., optimism for solvability, but where affective factors dominate); and, 4) pessimistic-affective (i.e., avoidance of systematic efforts to improve one's situation) (pp. 265-266). This typology has been explored in other studies of adults' ELIS activities (Copeland, 2011; Davenport, Richey, \& Westbrook, 2008), mainly using interview methods to examine participants' views and perspectives. In order to extend the current analysis to examine this typology, interviews with children or other techniques designed to capture their personal outlooks on their ELIS activities, would be required. Further, the theory of ELIS has evolved in the field to include a variety of other tasks and activities beyond those captured in the observational data. By triangulating the data sources to explore child participants' perspectives on their ELIS activities (e.g., through interviews), a richer picture of their daily information practices and perspectives can emerge.

\section{Acknowledgements}

The project "Interacting with knowledge, interacting with people: Web searching in early childhood" was funded by the Australian Research Council (DP110104227). The Chief Investigators are Susan Danby, Karen Thorpe, and Christina Davidson. The project was approved by the human research ethics committees of Queensland University of Technology (Ref No: 1100001480) and Charles Sturt University (Ref No: 2012/40). We thank the teachers, children and families of the Crèche and Kindergarten Association for their participation in this study.

\section{References}

Agosto, D. E., \& Hughes-Hassell, S. (August 01, 2006). Toward a model of the everyday life information needs of urban teenagers, part 1: Theoretical model. Journal of the American Society for Information Science and Technology, 57, 10, 1394-1403.

Barack, L. (2013). The early bird: How Sesame workshop is adapting its revolutionary educational content for devices. School Library Journal, 59(7), 18. 
Bilal, D. (2002). Children's use of the Yahooligans! web search engine. III. Cognitive and physical behaviors on fully self-generated search tasks. Journal of the American Society for Information Science and Technology, 53, 1170-1183.

Bilal, D. (2005). Children's information seeking and the design of digital interfaces in the affective paradigm. Library Trends, 54, 197-208.

Björneborn, L. (2008). Serendipity dimensions and users' information behaviour in the physical library interface. Information Research, 13(4). Retrieved from http://www.informationr.net/ir/13-4/paper370.html

Bodrova, E., \& Leong, D. (1998). Development of dramatic play in young children and its effects on self-regulation: The Vygotskian approach. Journal of Early Childhood Teacher Education, 19, 2, 115-124.

Branscombe, N. A., Burcham, J. G., Castle, K., \& Surbeck, E. (2014). Early childhood curriculum: A constructivist perspective (2nd ed.). New York, NY: Routledge.

Bredekamp, S., \& Copple, C. (1997). Developmentally appropriate practice in early childhood programs. Washington, DC: National Association for the Education of Young Children.

Buckingham, D., \& Scanlon, M. (2001). Parental pedagogies: An analysis of British "edutainment" magazines for young children. Journal of Early Childhood Literacy, 1(3), 281-299.

Burnett, C. (2010). Technology and literacy in early childhood educational settings: A review of research. Journal of Early Childhood Literacy, 10,3, 247-270

Burnett, C., \& Merchant, G. (2014) Points of view: Reconceptualising literacies through an exploration of adult and child interactions in a virtual world. Journal of Research in Reading, 37(1), 36-50. doi:10.1111/jrir.12006

Case, D. O., \& Given, L. M. (Eds.) (2016). Looking for information: A survey of research on information seeking, needs, and behavior (4th ed.). London, UK: Emerald Press.

Charlesworth, R. (2011). Understanding child development (8th ed.). Belmont, CA: Cengage Learning.

Clements, D. H., \& Sarama, J. (2007). Effects of a preschool mathematics curriculum: Summative research on the "Building Blocks" project. Journal for Research in Mathematics Education, 38, 2, 136-163

Common Sense Media. (2013). Zero to eight: Children's media use in America 2013. Retrieved from http://www.commonsensemedia.org/file/zero-to-eight-2013pdf-0/download 
Connoway, L.S., Dickey, T.J., \& Radford, M.L. (2011). "If it is too inconvenient I'm not going after it": Convenience as a critical factor in information-seeking behaviors. Library \& Information Science Research, 33, 179-190. doi:10.1016/j.lisr.2010.12.002

Cooper, L. Z. (2002). A case study of information-seeking behavior in 7-year-old children in a semistructured situation. Journal of the American Society for Information Science and Technology, 53, 904-922. doi:10.1002/asi.10130

Copeland, A. J. (2011). Analysis of public library users' digital preservation practices. Journal of the American Society for Information Science and Technology, 62, 1288-1300. doi:10.1002/asi.21553

Courage, M. L., \& Setliff, A. E. (2009). Debating the impact of television and video material on very young children: Attention, learning, and the developing brain. Child Development Perspectives, 3(1), 72-78

Danby, S., Davidson, C., Ekberg, S., Breathnach, H., \& Thorpe, K. (2016). "Let's see if you can see me": making connections with Google Earth" ${ }^{\mathrm{TM}}$ in a preschool classroom. Children's Geographies, 14(2), 141-157. doi:10.1080/14733285.2015.1126231

Danby, S., Davidson, C., Theobald, M., Houen, S., \& Thorpe, K. (in press). Playing with technology: Young children making sense of technology as part of their everyday social worlds. In D. Pike, S. Lynch, \& C. A. Beckett (Eds.), State of play: Multidisciplinary perspectives on play. New York, NY: Springer.

Danby, S., Davidson, C., Theobald, M., Scriven, B., Cobb-Moore, C., Houen, S., Grant, S., Given, L.M., \& Thorpe, K. (2013). Talk in activity during young children's use of digital technologies at home. Australian Journal of Communication, 40(2), 83-99.

Davenport, D. D., Richey, J., \& Westbrook, L. (2008). E-government access to social service information: State web resources for domestic violence survivors. Journal of the American Society for Information Science \& Technology, 59, 903-915. doi:10.1002/asi.20787

Davidson, C. (2010). "Click on the big red car": The social organization of playing a Wiggles computer game. Convergence: The International Journal of Research into New Media Technologies, 16(4), 375-394.

Davidson, C. (2012a). When "yes turns to "no": Young children's disputes during computer game playing at home. In S. Danby \& M. Theobald (Eds.), Disputes in everyday life: The social and moral orders of children and young people (Vol. 15, pp. 355-376). Bingley, UK: Emerald.

Davidson, C. (2012b). Seeking the green basilisk lizard: Acquiring digital literacy practices in the home. Journal of Early Childhood Literacy, 12(1), 24-45.

doi:10.1177/1468798411416788 
Davidson, C., Danby, S., Given, L. M., \& Thorpe, K. (in press). Producing contexts for young children's digital technology use: Web searching during adult-child interactions at home and preschool. In S. Danby, M. Fleer, C. Davidson, \& M. Hatzigianni (Eds.), Digital childhood. New York, NY: Springer.

Davidson, C., Danby, S., Given, L. M., \& Thorpe, K. (2014). Talk about a YouTube video in preschool: The mutual production of shared understanding for learning with digital technology. Australasian Journal of Early Childhood, 39(3), 76-83.

Desmond, R., \& Bagli, M. T. (2008). Parent's and young children's communication during computer use: Beyond mediation. Simile, 8(3), 1-14. doi:10.3138/sim.8.3.002.

Dhingra, R., Sharma, N., \& Kour, M. (2009). Relationship between parental perception and young children's usage of computers. Journal of Human Ecology, 28(3), 167-170.

Dresang, E. T. (2005). Access: The information-seeking behavior of youth in the digital environment. Library Trends, 54(2), 178-196. doi:10.1353/lib.2006.0015

Ekberg, S., Danby, S., Davidson, C., \& Thorpe, K. J. (2016). Identifying and addressing equivocal trouble in understanding within classroom interaction. Discourse Studies, 18(1), $3-24$.

Eliason, C. F., \& Jenkins, L. T. (2012). A practical guide to early childhood curriculum. Boston, MA: Pearson.

Elkind, D. (2009). Let’s play!. Odyssey, 18(6), 8.

Ellis, K., \& Blashki, K. (2004). Toddler techies: A study of young children's interaction with computers. Information Technology in Childhood Education Annual, 2004(1), 77-96.

Erdelez, S. (2005). Information encountering. In E. Fisher, Karen, S. Erdelez, \& L. E. F. McKechnie (Eds.), Theories of information behavior (pp. 179-184). Medford, NJ: Information Today, Inc.

Evaldsson, A. C., \& Corsaro, W. A. (1998). Play and games in the peer cultures of preschool and preadolescent children: An interpretative approach. Childhood, 5(4), 377-402.

Evans, D. W., Leckman, J. F., Carter, A., Reznick, J. S., Henshaw, D., King, R., \& Pauls, D. (1997). Ritual, habit, and perfectionism: The prevalence and development of compulsivelike behavior in normal young children. Child Development, 68(1), 58-68.

Fisher, K. E., Naumer, C., \& Durrance, J. C. (2005). Something old, something new: Preliminary findings from an exploratory study about people's information habits and information grounds. Information Research, 10(2). Retrieved from informationr.net/ir/102/paper223.html 1/13 
Foss, E., Druin, A., Brewer, R., Lo, P., Sanchez, L., Golub, E., \& Hutchinson, H. (2012). Children's search roles at home: Implications for designers, researchers, educators, and parents. Journal of the American Society for Information Science and Technology, 63, 558-573. doi:10.1002/asi.21700

Foster, A., \& Ford, N. (2003). Serendipity and information seeking: An empirical study. Journal of Documentation, 59, 321-340. doi:10.1108/00220410310472518

Gimbert, B., \& Cristol, D. (2004). Teaching curriculum with technology: Enhancing children's technological competence during early childhood. Early Childhood Education Journal, 31(3), 207-216.

Given, L. M. (2002). The academic and the everyday: Investigating the overlap in mature undergraduates' information-seeking behaviors. Library \& Information Science Research 24, 17-29.

Given, L. M., \& Leckie, G. J. (2003). Sweeping the library: Mapping the social activity space of the public library. Library \& Information Science Research, 25, 365-385.

Given, L. M., Winkler, D.C., Willson, R., Davidson, C., Danby, S., \& Thorpe, K. (2016). Parents as co-researchers at home: Using an observational method to document young children's technology use. International Journal of Qualitative Methods, 15(1). doi:10.1177/1609406915621403

Given, L. M., Winkler, D. C., Willson, R., Davidson, D., Danby, S., \& Thorpe, K. (2014). Documenting young children's technology use: Observations in the home. In A. Groves (Ed.), Connecting collections, cultures and communities: Proceedings of the $77^{\text {th }}$ Annual Meeting of the American Society for Information Science and Technology. Retrieved from http://onlinelibrary.wiley.com/doi/10.1002/meet.2014.14505101028/epdf

Green, L., Brady, D., Ólafsson, K., Hartley, J. A. E., \& Lumby, C. (2011). Risks and safety for Australian children on the Internet: Full findings from the AU Kids Online survey of 9-16 year olds and their parents. Cultural Science Journal, 4(1), 1-73.

Gutnick, A. L., Robb, M., Takeuchi, L., Kotler, J., Bernstein, L., \& Levine, M. H. (2011). Always connected. Retrieved from http://www.joanganzcooneycenter.org/wpcontent/uploads/2011/03/jgcc_alwaysconnected.pdf

Holloway, D., Green, L., \& Livingstone, S. (2013). Zero to eight. Young children and their internet use. Retrieved from the London School of Economics website: http://eprints.1se.ac.uk/52630/1/Zero_to_eight.pdf

Hughes, F. P. (2010). Children, play, and development. Los Angeles, CA: Sage.

Kalogiannakis, M., \& Zaranis, N. (2012). Preschool science education with the use of ICT: A case study. In C. Bruguière, A. Tiberghien \& P. Clément (Eds), Proceedings of the ESERA 
2011 Conference. Science learning and Citizenship, Part 4: ICT and other resources for teaching/learning science (P. Marzin \& J. Lavonen, Co-editors for Part 4), Lyon, 5-9 September 2011, 56-62. Retrieved from https://tuhat.halvi.helsinki.fi/portal/files/21970249/ebook_esera2011_Strand4.pdf

Labbo, L. D., Reinking, D. (2003). Computers and early literacy education. In N. Hall, J. Larson, \& J. Marsh (Eds.), Handbook of early childhood literacy (pp. 338-354). Thousand Oaks, CA: Sage.

Lankshear, C., \& Knobel, M. (2003). New technologies in early childhood literacy research: A review of research. Journal of Early Childhood Literacy, 39(1), 59-82.

Large, A., Beheshti, J., \& Rahman, T. (2002). Gender differences in collaborative web searching behavior: An elementary school study. Information Processing and Management, 38, 427443. doi:10.1016/S0306-4573(01)00034-6

Large, A., Nesset, V., \& Beheshti, J. (2008). Children as information seekers: What researchers tell us. New Review of Children's Literature and Librarianship, 14(2), 121-140. doi:10.1080/13614540902812631

Lenhart, A., Purcell, K., Smith, A., \& Zickuhr, K. (2010). Social media \& mobile Internet use among teens and young adults. Retrieved from http://www.pewinternet.org/files/oldmedia//Files/Reports/2010/PIP_Social_Media_and_Young_Adults_Report_Final_with_top lines.pdf

Levin, E. (2011). Child development. In S. Goldstein \& J. A. Naglieri (Eds.), Encyclopedia of child behavior and development (pp. 337-339). Boston, MA: Springer US. doi:10.1007/978-0-387-79061-9_523

Lieberman, D. A., Fisk, M. C., \& Biely, E. (2009). Digital games for young children ages three to six: From research to design. Computers in the Schools, 26(4), 299-313.

Lloyd, A. (2011). Trapped between a rock and a hard place: What counts as information literacy in the workplace and how is it conceptualized? Library Trends, 60(2), 277-296.

Lloyd, A. (2007). Learning to put out the red stuff: Becoming information literate through discursive practice. The Library Quarterly, 77(2), 181-198.

Lu, Y. L. (2010). Children's information seeking in coping with daily-life problems: An investigation of fifth- and sixth-grade students. Library \& Information Science Research, 32, 77-88. doi:10.1016/j.lisr.2009.09.004

Madden, M., Lenhart, A., Duggan, M., Cortesi, S., \& Gasser, U. (2013). Teens and technology 2013. Retrieved from http://www.pewinternet.org/files/oldmedia//Files/Reports/2013/PIP_TeensandTechnology2013.pdf 
Marsh, J. (2005). Ritual, performance and identity construction: Young children's engagement with popular culture and media texts. In J. Marsh (Ed.), Popular culture, new media and digital literacy in early childhood (pp. 28-50). London, UK: Routledge Falmer.

Marsh, J. (2006). Popular culture in the literacy curriculum: A Bourdieuan analysis. Reading Research Quarterly, 41(2), 160-174. DOI: 10.1598/RRQ.41.2.1

Marsh, J., \& Bishop, J. (2012). Rewind and replay? Television and play in the 1950s/1960s and 2010s. International Journal of Play, 1(3), 279-291. doi:10.1080/21594937.2012.741431

Marsh, J., Hannon, P., Lewis, M., \& Ritchie, L. (2015). Young children's initiation into family literacy practices in the digital age. Journal of Early Childhood Research, 1-14. doi: $10.1177 / 1476718 X 15582095$

McKechnie, L. E. F. (2004). "I'll keep them for my children" (Kevin, nine years): Children's personal collections of books and other media. The Canadian Journal of Information and Library Science, 28(4), 73-88.

McKenzie, P. J. (2003). A model of information practices in accounts of everyday-life information seeking. Journal of Documentation, 59, 19-40. doi:10.1108/00220410310457993

Meyers, E. M., Fisher, K. E., \& Marcoux, E. (2009). Making sense of an information world: The everyday-life information behavior of preteens. The Library Quarterly, 79, 301-341.

Miller, D. J., \& Robertson, D. P. (2010). Using a games console in the primary classroom: Effects of 'Brain Training' programme on computation and self-esteem. British Journal of Educational Technology, 41(2), 242-255.

Ofcom. (2013). Children and parents: Media use and attitudes report. Retrieved from https://www.ofcom.org.uk/data/assets/pdf_file/0024/78513/childrens_parents_nov2015.pdf ?lang=cym

Olsson, M. R. (2010). The play's the thing: Theater professionals make sense of Shakespeare. Library \& Information Science Research, 32, 272-280. doi:10.1016/j.lisr.2010.07.009

Ooi, K., \& Liew, C. L. (2011). Selecting fiction as part of everyday life information seeking. Journal of Documentation, 67, 748-772. doi:10.1108/00220411111164655

Park, M., \& Lee, J. Y. (2013). The role of information for people planning for retirement. Libri, 63(1), 57-71. doi:10.1515/libri-2013-0005

Plowman, L., Stephen, C., \& McPake, J. (2010a). Growing up with technology: Young children learning in a digital world. London, UK: Routledge. 
Plowman , L., Stephen, C., \& McPake, J. (2010b). Supporting young children's learning with technology at home and in preschool. Research Papers in Education, 25(1), 93-113.

Plowman, L., Stevenson, O., McPake, J., Stephen, C., \& Adey, C. (2011). Parents, pre-schoolers and learning with technology at home: Some implications for policy. Journal of Computer Assisted Learning, 27(4), 361-371. doi:10.1111/j.1365-2729.2011.00432.x

Ross, C. S. (1999). Finding without seeking: The information encounter in the context of reading for pleasure. Information Processing \& Management, 35, 783-799. doi:10.1016/S03064573(99)00026-6

Savolainen, R. (1995). Everyday life information seeking: Approaching information seeking in the context of "way of life." Library \& Information Science Research, 17, 259-94.

Savolainen, R. (2004). Everyday life information seeking. In M.A. Drake (Ed.), Encyclopedia of library and information science (pp. 1-9). New York, NY: Marcel Dekker.

Savolainen, R. (2007). Information behavior and information practice: Reviewing the "umbrella concepts" of information- seeking studies. The Library Quarterly, 77(2), 109-132.

Schlembach, S. (2012). Parent's beliefs, attitudes and behaviors: An examination into the interactions between parents and their young children during household screen media use (Unpublished doctoral dissertation). University of Cincinnati, Ohio. Retrieved from http://etd.ohiolink.edu/view.cgi/Schlembach Sue.pdf?ucin1337363793

Scriven, B., Davidson, C., Danby, S., Thorpe, K., and Given, L. M. (2013, September). “Barbie in a mermaid tale": The social accomplishment of play through simultaneous onscreen and offscreen actions. Paper presented at Narrative pragmatics-Culture, cognition, context: The 13th International Pragmatics Conference, 8-13 September, New Delhi, India.

Somerville, M., \& Lloyd, A. (2006). Codified knowledge and embodied learning: The problem of safety training. Studies in Continuing Education, 28(3), 279-289.

Spink, A., \& Heinström, J. (2011). Information behaviour development in early childhood. In A. Spink \& J. Heinström (Eds.), New direction in information behaviour (pp. 245-256). doi:10.1108/S1876-0562(2011)002011a013

Spink, A., Danby, S., Mallan, K., \& Butler, C. (2010). Exploring young children's web searching and technoliteracy. Journal of Documentation, 66, 191-206.

doi:10.1108/00220411011023616

Stephen, C., McPake, J., Plowman, L., \& Berch-Heyman, S. (2008). Learning from the children: Exploring preschool children's encounters with ICT at home. Journal of Early Childhood Research 6(2), 99-117. Retrieved from http://ecr.sagepub.com/cgi/content/abstract/6/2/99 doi: $10.1177 / 1476718 x 08088673$ 
Theobald, M., Danby, S., Davidson, C., Houen, S., Scriven, B., \& Thorpe, K. (2016). How talk and interaction unfold in a digitally enabled preschool classroom. Australian Journal of Linguistics, 36(2), 189-204. doi:10.1080/07268602.2015.1121530

Thorpe, K., Hansen, J., Danby, S., Zaki, F. M., Grant, S., Houen, S., Davidson, C., \& Given, L. M. (2015). Digital access to knowledge in the preschool classroom: Reports from Australia. Early Childhood Research Quarterly, 32, 174-182. doi:10.1016/j.ecresq.2015.04.001

Todd, R. (2003). Adolescents of the information age: Patterns of information seeking and use, and implications for information professionals. School Libraries Worldwide, 9(2), 27-46.

Trawick-Smith, J. W. (1997). Early childhood development: A multicultural perspective. New Jersey, NJ: Merrill.

Vandewater, E. A., Rideout, V. J., Wartella, E. A., Huang, X., Lee, J. H., \& Shim, M. (2007). Digital childhood: Electronic media and technology use among infants, toddlers, and preschoolers. Pediatrics, 119(5), e1006-15. doi:10.1542/peds.2006-1804

Veinot, T. (2007). "The eyes of the power company": Workplace information practices of a vault inspector. The Library Quarterly, 77, 157-179. doi:10.1086/517842

Verenikina, I., \& Kervin, L. (2011). iPads, digital play and pre-schoolers. He kupu, 2(5), 4-19.

Westbrook, L. (2009). Crisis information concerns: Information needs of domestic violence survivors. Information Processing \& Management, 45, 98-114. doi:10.1016/j.ipm.2008.05.005.

Willett, R., Robinson, M., \& Marsh, J. (Eds.). (2009). Play, creativity and digital cultures. London, UK: Routledge.

Yelland, N. J. (2010a). New technologies, playful experiences and multimodal learning. In I. Berson \& M. Berson (Eds.), High tech tots: Childhood in a digital world (pp. 5-22). Charlotte, NC: Information Age Publishing.

Yelland, N. J. (2010b). Multiliteracies and learning in a new age. In J. Fletcher \& F. Parkhill (Eds.), Motivating literacy learners (pp. 60-77). Auckland, NZ: New Zealand Reading Association.

Zevenbergen, R., \& Logan, H. (2008). Computer use by preschool children: Rethinking practice as digital natives come to preschool. Australian Journal of Early Childhood, 33(1), 37-44. 